\title{
Herniación del canal de Nuck en lactante
}

\author{
Nuck's canal herniation in infants \\ Juan Ramón y Cajal-Calvo, ${ }^{*}$ Carlota María Bello-Franco, ${ }^{*}$ Ana Revuelta-Cabello, ${ }^{\ddagger}$ David Ibáñez-Muñoz*
}

Citar como: Ramón y Cajal-Calvo J, Bello-Franco CM, Revuelta-Cabello A, Ibáñez-Muñoz D. Herniación del canal de Nuck en lactante. Acta Med. 2020; 18 (4): 435-436. https://dx.doi.org/10.35366/97278

Lactante de dos meses que es traída a urgencias por un aumento de volumen en la región inguinal derecha desde hacía unas horas. En la exploración física se apreció dicho aumento de volumen en la región inguinal derecha móvil, aparentemente no doloroso y de $1 \times 1$ $\mathrm{cm}$ de diámetro.

Se decidió realizar una ecografía de la región inguinal de urgencia que puso de manifiesto la existencia de herniación del ovario derecho (hernia del canal de Nuck) con orificio de apertura de unos $8 \mathrm{~mm}$. El ovario presentaba un aumento de tamaño para la edad de la paciente con vascularización disminuida, sin poder descartar compromiso o torsión parcial del mismo. A pesar del llanto, no se observaba herniación de las asas intestinales a través del orificio herniario. Se procedió a la valoración por el Servicio de Cirugía Pediátrica que decidió someter a la paciente a una intervención quirúrgica de urgencia (Figura 1).

Las hernias inguinales en el recién nacido pueden ocurrir con una frecuencia de 1-2\%. ${ }^{1}$ Las hernias del canal de Nuck pueden incluir cualquiera de los contenidos peritoneales: mesenterio, fluidos, vejiga y ovario. A pesar de la posibilidad de una reducción espontánea, la presencia de estas estructuras orgánicas en el canal inguinal la hacen

Figura 1:

A y B) Ecografía abdominal plano axial, donde se

visualiza el ovario derecho claramente definido con

folículos en su interior. Se puede apreciar cómo el ovario se sitúa anterior a la vejiga (v) y la pared anterior abdominal. Se objetiva además la poca vascularización del ovario con un pobre registro Doppler, que es indicativo de una posible torsión ovárica asociada.
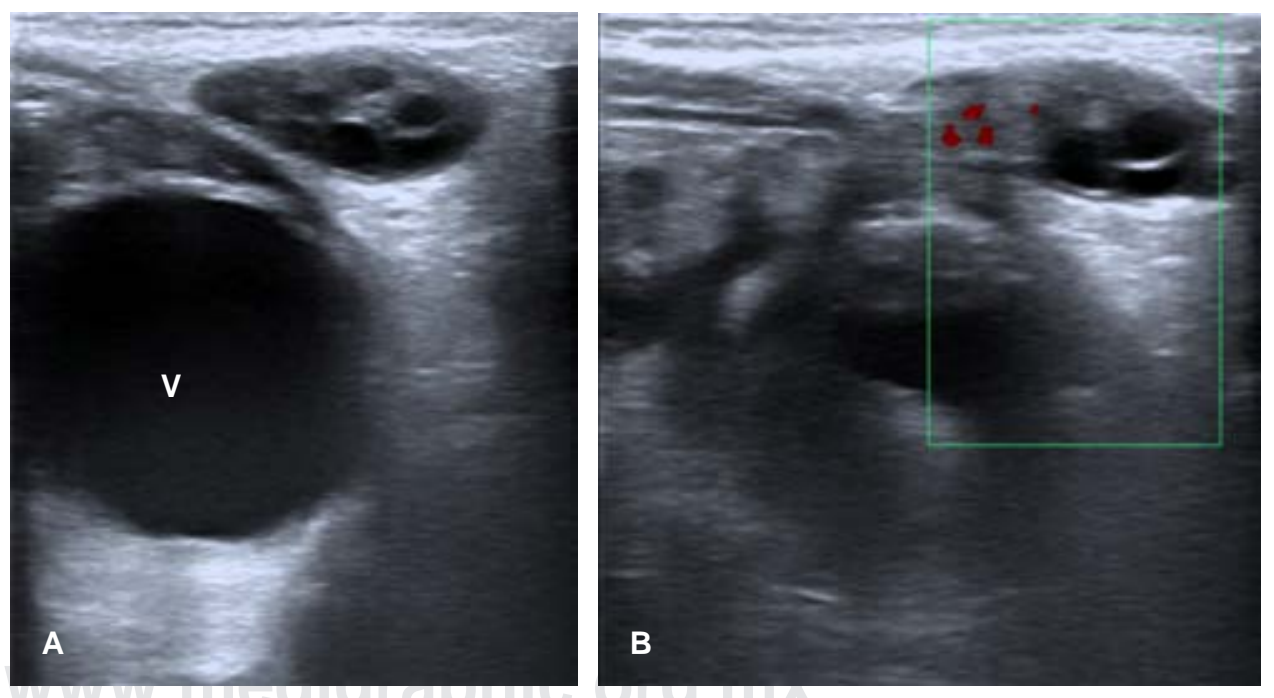

* Servicio de Radiodiagnóstico.

* Servicio de Pediatría.

Hospital Clínico Universitario Lozano Blesa.

Zaragoza. España.
Correspondencia:

Dr. Juan Ramón y Cajal Calvo

Correo electrónico: jramonycajalc@gmail.com

Aceptado: 22-06-2020.

www.medigraphic.com/actamedica

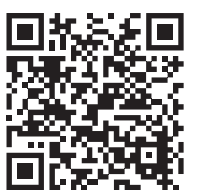


Figura 2:

Imagen

ecográfica

abdominal

de la misma

paciente donde

se localiza el

ovario izquierdo

en su ubicación

habitual dentro

de la cavidad

peritoneal

posterior a la

vejiga.

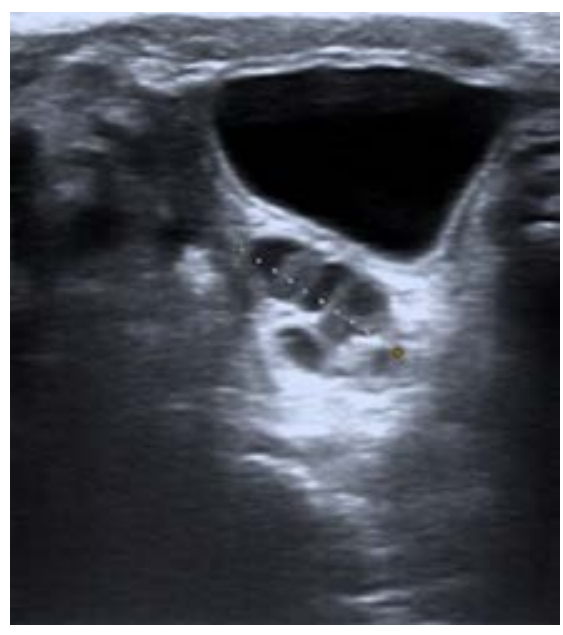

improbable, inclusive aumentan el riesgo de incarceración. En el caso del ovario, puede producirse una torsión e infarto (mayor riesgo se asocia a herniación de la trompa) (Figura 2). ${ }^{2}$
Puede ser una tumoración asintomática o asociar dolor, signos de inflamación y compromiso vascular. La localización más frecuente es en lado derecho (60\%) y la edad de presentación más habitual se encuentra entre uno y seis años. ${ }^{3}$

La ecografía es la técnica de elección, la mayoría de estas hernias son de un tamaño inferior a $3 \mathrm{~cm}$. El tratamiento es quirúrgico dado el riesgo de torsión y la poca probabilidad de reducción espontánea.

\section{REFERENCIAS}

1. Huang CS, Luo CC, Chao HC, Chu SM, Yu YJ, Yen JB. The presentation of asymptomatic palpable movable mass in female inguinal hernia. Eur J Pediatr. 2003; 162 (7-8): 493-495.

2. Dal Mo Yang, Hyun Cheol Kim, Sang Won Kim, Sung Jig Lim, Seung Jin Park, Joo Won Lim. Ultrasonographic diagnosis of ovarycontaining hernias of the canal of Nuck. Ultrasonography. 2014; 33: 178-183.

3. Nasser H, King M, Rosenberg HK, Rosen A, Wilck E, Simpson WL. Anatomy and pathology of the canal of Nuck. Clin Imaging. 2018; 51: 83-92. 